\title{
EDUCAÇÃO AMBIENTAL COM ESTUDANTES E FAMÍLIAS NA GESTÃO DOS RESÍDUOS SÓLIDOS URBANOS
}

\author{
Adir Silvério Cembranel ${ }^{1}$ \\ Mafalda Nesi Francischett ${ }^{2}$ \\ Carla Regina Rodrigues ${ }^{3}$
}

RESUMO: O objetivo deste trabalho foi avaliar como a Educação Ambiental EA, direcionada a Resíduos Sólidos Urbanos - RSU, influencia os estudantes e as suas famílias. A pesquisa ocorreu com 147 estudantes e 25 famílias de uma escola de ensino fundamental, no município de Manfrinópolis/PR. Na primeira etapa foram realizados levantamentos quantitativos e qualitativos dos RS gerados na escola e nas famílias e a análise das respostas a um questionário que buscou identificar o conhecimento dos sujeitos a respeito do tema. $\mathrm{Na}$ segunda etapa foram realizadas atividades de EA. Na terceira ocorreram novamente os levantamentos qualitativos e quantitativos dos RSU e a aplicação do questionário. A EA não teve resultado positivo entre as famílias, no entanto na escola ocorreu expressiva melhoria na gestão dos resíduos.

Palavras-chave: Meio Ambiente; Resíduos Sólidos Urbanos; Educação Ambiental; Atividades Escolares Lúdicas.

\footnotetext{
1 Universidade Tecnológica Federal do Paraná. E-mail: adircembranel@utfpr.edu.br

2 Universidade Estadual do Oeste do Paraná. E-mail: mafalda@wln.com.br

3 Universidade Tecnológica Federal do Paraná. E-mail: carlamanfri@hotmail.com
} 


\section{Introdução}

Os Resíduos Sólidos Urbanos - RSU resultam das atividades diárias da sociedade e são compostos por sobras de alimentos, por materiais recicláveis, dentre outras substâncias descartadas pelo homem (LIMA, 2004). O gerenciamento dos RSU deve ser preocupação de todos, uma vez que os efeitos da falta de controle ou do controle inadequado causam prejuízos que afetam o contexto relacionado à qualidade de vida. Dessa forma, as alternativas de gestão precisam considerar a realidade local, procurando potencializar a reutilização dos recursos disponíveis (FERREIRA, 2000).

Países como o Brasil apresentam situação preocupante quanto aos serviços de limpeza urbana, pois são incapazes de coletar toda a produção de RSU. Assim, os resíduos sólidos que restam não coletados resultam na deposição em vias públicas, em terrenos baldios e próximos ou dentro dos cursos d'água (NEVES; TUCCI, 2011).

A Educação Ambiental - EA, como essencialmente sendo processo pedagógico, pode ser a base para ações coletivas para a adequada gestão desses resíduos. Entretanto, precisa ser trabalhada e estruturada de modo que aborde com interesse e visibilidade a quem recebe as informações. Assim, EA precisa ser criativa, lúdica, afetiva e dialógica (TOFFOLO; FRANCISCHETT, 2012).

Metodologias que buscam inovar a EA devem considerar aspectos afetivos e lúdicos dos participantes, principalmente no processo de ensinoaprendizagem escolares. As atividades lúdicas e as brincadeiras estimulam o processo cognitivo das crianças, pois por meio de fantasias e de brincadeiras o aprendizado é mais intenso que nas atividades tradicionais (VYGOTSKY, 2007; BARCELOS, 2008).

As atividades com EA podem expor e possibilitar ao estudante situações que sejam necessárias à pesquisa, proporcionando ao estudante conhecer as suas capacidades e as suas limitações. Além disso, a EA pode promover 0 diálogo e exercer ações de liderança com desenvolvimento de valores éticos, entre outros desafios (DOHME, 2008).

Desse modo, tratar do tema significativamente é possibilitar e permitir maior envolvimento e comprometimento dos sujeitos no processo. Para tal, é necessário se valer de vários recursos que podem possibilitar o aprendizado, desde mídias educativas, como quadro-negro, jogos educativos, filmes e até uma planejada ação investigativa de campo.

A EA estimula os sujeitos para que possam transformar para melhor o ambiente em que vivem, isso por meio de uma adequada definição de valores e do correto planejamento de atitudes. Mesmo assim, no entanto, a EA precisa acontecer nas escolas continuamente, mas não somente com as crianças. É preciso sensibilizar também os adultos, pois que é da ação deles que ocorre a degradação do meio em que vivem (TOFFOLO; FRANCISCHETT, 2012). 
Nesse contexto, o objetivo deste artigo é trazer resultados de pesquisa referentes a um processo de Educação Ambiental para a gestão de RSU direcionada a estudantes e a suas famílias no município de Manfrinópolis/PR.

\section{Material e Métodos}

\section{Local e população de estudo}

A pesquisa foi realizada no ano de 2014, no município de Manfrinópolis, cuja população é de 3.127 habitantes e está situado na região sudoeste do estado do Paraná. Em média, as famílias urbanas do município são constituídas por três pessoas. Aproximadamente 200 famílias residem na área urbana do território (IBGE, 2013). O estudo foi desenvolvido com 147 alunos do $1^{\circ}$ ao $5^{\circ}$ ano do Ensino Fundamental da Escola Municipal Eça de Queirós - única com ensino fundamental na sede do município - e com 25 famílias dos estudantes da escola. Assim, o estudo atingiu, aproximadamente, $20 \%$ da população urbana.

\section{Descrição das atividades}

A primeira etapa da pesquisa buscou identificar a compreensão dos estudantes e das famílias acerca da gestão dos RSU de três formas. Quanto à primeira, as famílias, definidas por sorteio, foram orientadas a armazenar os resíduos, exceto resíduos orgânicos e de banheiro, de forma habitual, entre os dias 28 de abril a 2 de maio de 2014. Após esse período foram realizadas análises quantitativas e qualitativas dos resíduos, com o propósito de estabelecer um parâmetro inicial da gestão dos resíduos adotada pelas famílias.

A análise quantitativa ocorreu por meio de pesagem (em $\mathrm{kg}$ ) e a qualitativa por observação da classe de resíduo e a forma de separação entre resíduos recicláveis e rejeitos produzidos por cada família. Na escola, adotou-se a mesma metodologia. Assim, os responsáveis pela limpeza e pela coleta dos resíduos receberam orientações para armazenar os resíduos gerados entre os dias 22 a 26 de abril de 2014, que foram analisados de forma qualitativa e quantitativa.

A segunda forma de identificação ocorreu por meio da análise do conteúdo e da metodologia das atividades sobre EA, praticadas, registradas e mencionadas no Projeto Político-Pedagógico - PPP da escola. A análise buscou identificar as ações voltadas à gestão de RSU.

Quanto à terceira forma de gestão de RSU, os alunos responderam a um questionário com nove (9) questões, elaborado com o propósito de verificar o conhecimento dos alunos com relação aos resíduos.

As ações desenvolvidas na primeira etapa foram utilizadas como parâmetro inicial dos hábitos, do nível de informação das famílias e do nível de formação dos estudantes na gestão dos resíduos. Essas ações serviram então 
de base para as ações de EA realizadas na segunda etapa da pesquisa, por meio de atividades com jogos, competições, vídeos, desenhos e gincana.

A segunda etapa da pesquisa ocorreu entre os dias 5 de maio e 4 de junho de 2014. Nesse período foram desenvolvidas, na escola, ações didáticopedagógicas de EA direcionadas a RSU. As atividades ocorreram duas vezes por semana, com duração de uma ou duas horas, de acordo com a metodologia proposta. As metodologias didático-pedagógicas desenvolvidas estão descritas no item Estratégias didático-pedagógicas das atividades de EA apresentado no artigo.

Após as práticas de EA, o questionário respondido na primeira etapa foi repetido, agora com o objetivo de avaliar a eficiência da EA na compreensão dos temas propostos. Para avaliar a influência dos estudantes nas famílias, quanto à gestão dos resíduos, realizou-se novamente levantamento investigativo, qualitativo e quantitativo. As famílias foram orientadas a armazenarem os resíduos produzidos no período de 9 a 13 de junho de 2014. Na avaliação da eficiência da EA com os estudantes na escola, os resíduos foram então armazenados nesse período para novo levantamento quantitativo e qualitativo.

A análise dos efeitos da EA entre os alunos e os familiares ocorreu confrontando os dados obtidos antes de e após as atividades educativas. Os dados foram tabulados de forma a apresentar os resultados das duas etapas. $\mathrm{Na}$ análise do questionário buscou-se identificar as diferenças entre as respostas antes de e após a EA. A análise quantitativa considerou o peso $(\mathrm{em} \mathrm{kg})$ dos resíduos gerados nas duas etapas da pesquisa, na escola e entre as famílias. Qualitativamente considerou-se a existência e/ou a forma de separação entre os resíduos recicláveis (vidro, papel, metal e plástico) e rejeitos (escola e famílias), conforme orientações repassadas durante as atividades realizadas na escola.

Para verificar a diferença estatisticamente significativa entre as quantidades de resíduos reciclados e rejeitos gerados pelas famílias, antes e após as ações na escola, os valores foram submetidos à análise estatística descritiva e teste comparativo de média Tukey a 5\% de significância.

\section{Estratégias didático-pedagógicas das atividades de EA}

As atividades, na escola, ocorreram em todas as turmas, separadamente. $\mathrm{Na}$ primeira semana foram realizadas atividades de sensibilização, buscando orientar os estudantes quanto às diferenças entre lixo e resíduo, tipos de tratamento dos resíduos sólidos, envolvendo reciclagem, incineração e compostagem. Além de atividades dialogadas acerca dos temas, ocorreu, por meio de multimídia, a apresentação dos vídeos "Tá limpo!" (KOENIG, 1991) e "Lixo: responsabilidade de cada um" (CDCC, 2002). Na sequência, os alunos realizaram atividades relacionados aos temas apresentados nos vídeos, conforme Figura 1.

revista brasileira de educação ambiental 


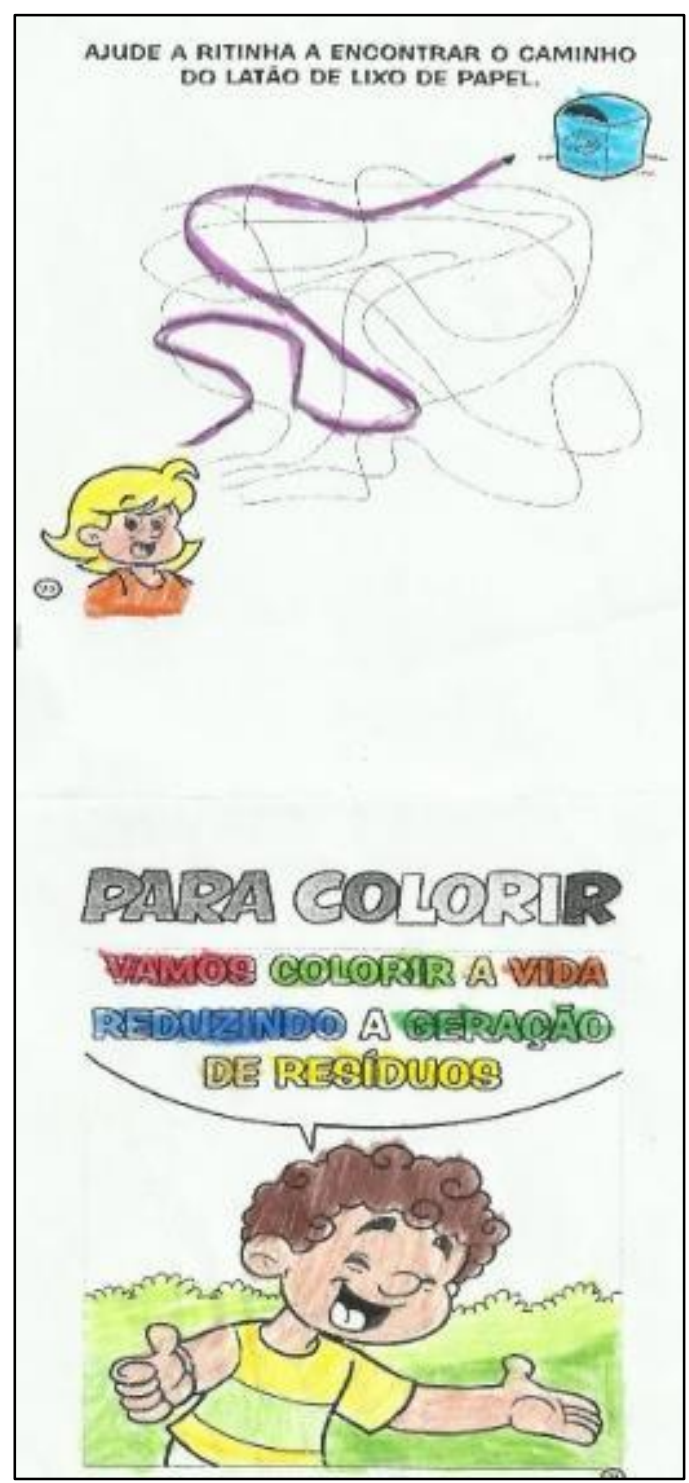

Figura 1: Atividades colorindo desenhos. Fonte: Arquivo pessoal (2014).

Na segunda semana, as atividades foram voltadas à orientação de coleta seletiva e do significado das cores dos coletores para a identificação e a separação dos resíduos, de acordo com a Resolução no 275/2001, do Conselho Nacional do Meio Ambiente - CONAMA. Por meio de projetor multimídia foram apresentadas imagens identificando as cores correspondentes a cada tipo de resíduo e orientações sobre a forma correta de segregação.

Na sequência foi proposto aos estudantes o desenvolvido de brinquedos com materiais recicláveis. Inicialmente foi construído um bilboquê (Figura 2a), fabricado com uma garrafa PET, barbante e bola de papel. Outro brinquedo desenvolvido foi o tabuleiro de jogo da velha, confeccionado com papelão, tampinha de garrafa PET e lápis de cor (Figura 2b). 

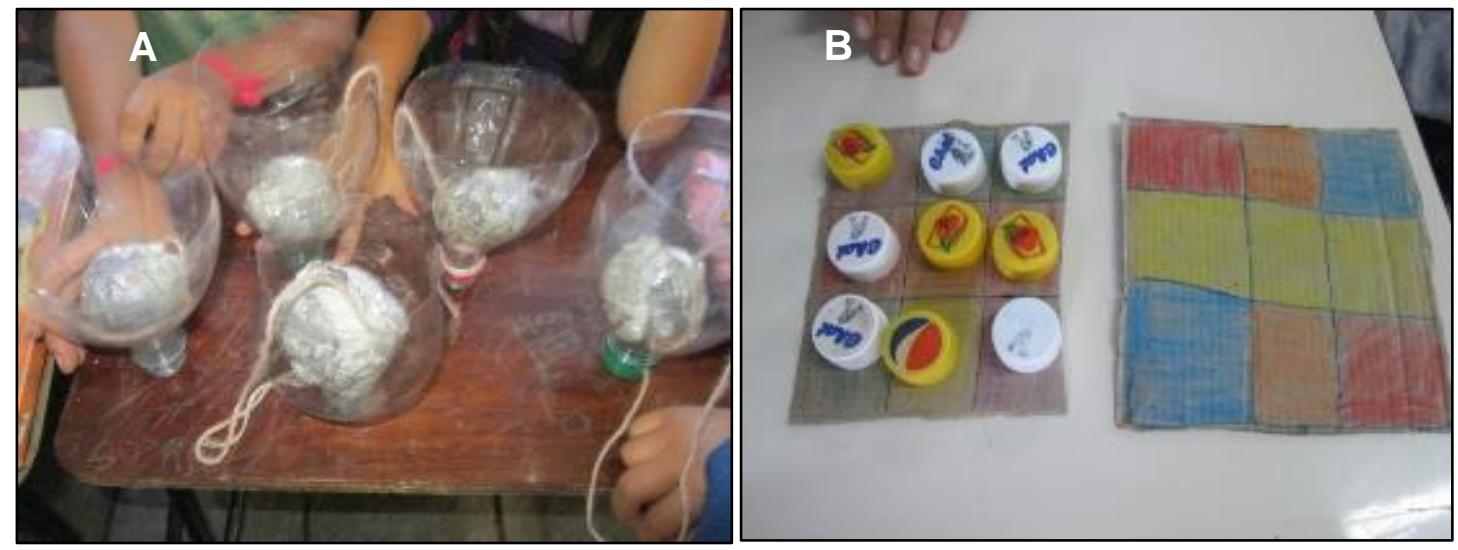

Figura 2: Elaboração do bilboquê (A) e tabuleiro de jogo da velha (B).

Fonte: Arquivo pessoal (2014).

A terceira semana foi destinada a apresentar alternativas de destino final dos resíduos e a origem de materiais recicláveis como: papel, plástico e vidro. A ação ocorreu por meio de apresentação dos vídeos em multimídia "Destinos do lixo" (CDCC, 2014) e "De onde vem?" (MEC, 2014), e por meio de palestra. No encerramento da dinâmica, os alunos foram orientados a desenvolverem desenhos referentes à coleta seletiva e relacionar a cor dos símbolos de reciclagem ao tipo de resíduo (Figura 3a).

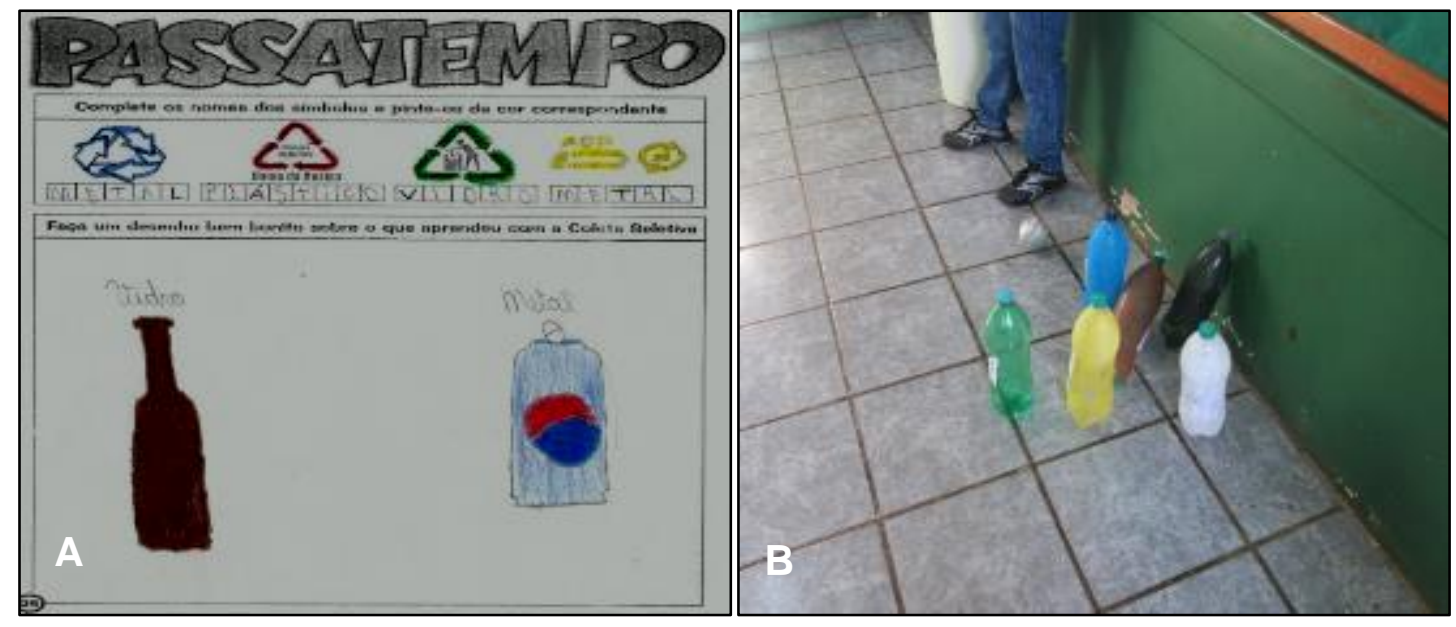

Figura 3: Desenhos coleta seletiva e reciclagem (A) e jogo de boliche (B).

Fonte: Arquivo pessoal (2014).

Durante a quarta semana foi desenvolvida uma gincana. A atividade teve o propósito de trabalhar os conceitos referentes a materiais recicláveis, rejeitos, coleta seletiva e compostagem, discutidos nas semanas anteriores. Os estudantes foram organizados em grupos de quatro a cinco. A primeira atividade desenvolvida foi a classificação dos RSU de acordo com o tipo e cores dos coletores, tudo em conformidade com a mencionada Resolução no 275/2001, do CONAMA. Os resíduos plásticos, os papéis, os vidros e os metais deveriam ser

Revbea, São Paulo, V. 14, № 1: 171-185, 2019. 
depositados nos coletores da cor correspondente. A cada acerto a equipe somava dez pontos, porém a cada erro perdia dez pontos.

$\mathrm{Na}$ segunda atividade, os grupos receberam uma folha com cinco questões dissertativas. A cada resposta correta o grupo conquistava cinquenta pontos. As perguntas foram: Quais são os tipos de tratamento dos resíduos sólidos? O que é rejeito? O que é coleta seletiva? O que é compostagem? Podemos classificar os resíduos recicláveis de acordo com as cores? Cite um exemplo de resíduo para lixeiras de cor azul, de cor vermelha, de cor amarela, de cor verde e de cor marrom. Os grupos tinham dez minutos para responder a todas as questões.

A terceira atividade foi 0 jogo de boliche (Figura 3b), que foi confeccionado com seis garrafas PET de dois litros. A bola foi confeccionada usando jornal e fita adesiva. Cada integrante do grupo realizou um arremesso. Cada garrafa derrubada somava pontos para o grupo, porém a pontuação era diferente de garrafa a outra, variando de um a seis.

A última atividade foi o jogo da memória, este confeccionado com copos de iogurte e com figuras de resíduos (Figura 4). Cada grupo escolheu um representante por meio de sorteio, e os escolhidos competiram entre si. $\mathrm{O}$ vencedor da última partida do jogo da memória somou 50 pontos a para sua equipe. No término da gincana realizou-se o somatório dos pontos de cada equipe.

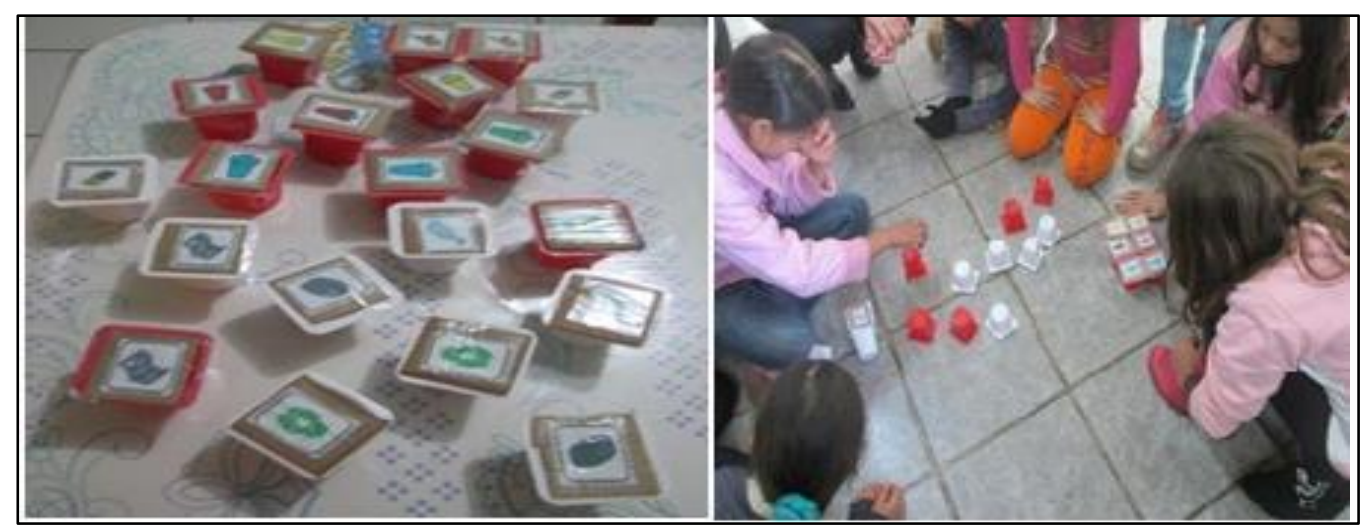

Figura 4: Jogo da memória. Fonte: Arquivo pessoal (2014).

\section{Resultados e Discussão}

Assim como em grandes centros urbanos, os pequenos municípios sentem o impacto negativo da gestão inadequada dos resíduos sólidos urbanos e do processo de EA ineficiente, como pode ser constatado nesta pesquisa.

Dentre as 25 famílias selecionadas, três não realizaram as atividades acordadas, justificando esquecimento. Desse modo, a análise ocorreu com 22 famílias. Após o período determinado, os resíduos armazenados pelas famílias 
foram classificados em recicláveis e rejeitos. Considerou-se que rejeitos eram os resíduos sólidos que não apresentaram outras possibilidades senão apenas a deposição final ambientalmente adequada (BRASIL, 2010). Por sua vez, foram considerados resíduos recicláveis os materiais passiveis de retornar ao ciclo produtivo, como metais, papeis, plásticos e vidros (LIMA, 2004; RIBEIRO; MORELLI, 2009). Os resíduos orgânicos não foram quantificados devido às limitações de armazenagem durante o período estabelecido.

A maioria das famílias não realizou qualquer tipo de separação entre as classes de resíduos e, mesmo as que realizaram a separação, elas o realizaram de forma inadequada. Essa falta de cuidado é consequência, possivelmente, à inexistência de ações de EA e de coleta seletiva no município. Nesse ínterim, no entanto, os resíduos recicláveis geralmente são coletados por catadores autônomos, que comercializam esses materiais com empresas de reciclagem de outros municípios.

A Tabela 1 apresenta a quantidade de resíduos recicláveis e rejeitos gerados pelas famílias, antes de e após as ações na escola. Antes das atividades de EA, 14 famílias destinavam os resíduos orgânicos para coleta pública. Após a EA, esse número reduziu para 11 famílias, apresentando pequena alteração.

Tabela 1: Quantidade de resíduos (em kg) gerados pelas famílias antes de e após a EA

\begin{tabular}{lcccccccc}
\hline \multicolumn{4}{c}{ Antes da EA } & \multicolumn{5}{c}{ Após a EA } \\
\hline Resíduos & $\overline{\boldsymbol{X}}$ & DP & Mín & Máx & $\overline{\boldsymbol{X}}$ & DP & Mín & Máx \\
\hline Recicláveis & 0,250 & 0,906 & 0,000 & 3,000 & 0,450 & 1,643 & 0,000 & 6,000 \\
\hline Rejeitos & 1,00 & 1,577 & 0,00 & 5,100 & 0,475 & 1,732 & 0,000 & 6,500 \\
\hline $\bar{X}$
\end{tabular}

$\overline{\bar{X}}$ - Média das 22 amostras; DP - Desvio-Padrão; Mín - quantidade mínimo (kg); Máx quantidade máxima $(\mathrm{kg})$.

Fonte: Autores.

A análise estatística ANOVA, seguida de comparação múltipla de médias por meio do teste Tukey, a 5\% de significância, não identificou diferença estatisticamente significativa entre as quantidades de resíduos geradas pelas famílias antes de e após as atividades de EA.

A quantidade média (em $\mathrm{kg}$ ) de resíduos sólidos destinados à coleta pública no município de Manfrinópolis (1,250 kg antes da $E A)$ foi superior à média do estado do Paraná $(0,725 \mathrm{~kg}$ ) (ABRELPE, 2015), mesmo desconsiderando resíduos orgânicos, predominantes entre as famílias e de banheiro, não quantificados na pesquisa. Essa situação é típica em pequenos municípios devido à falta de recursos para a infraestrutura, falta de programas de EA e falta de coleta seletiva (ABES, 2012).

Nos levantamentos quantitativos realizados na escola, antes de e após a EA, os resultados foram diferentes aos identificados entre as famílias (Tabela 2).

revista brasileira educação ambiental 
Tabela 2: Quantidade de resíduos (em kg) gerados na escola antes de e após a EA

\begin{tabular}{cccccc}
\hline \multicolumn{2}{c}{ Anterior da Educação Ambiental } & \multicolumn{3}{c}{ Após a Educação Ambiental } \\
\hline Reciclável & Rejeito & Orgânico & Reciclável & Rejeito & Orgânico \\
0,00 & 38,30 & 0,00 & 2,85 & 14,90 & 5,00 \\
\hline
\end{tabular}

Fonte: Autores.

Antes das ações de EA não foram identificadas ações ou estruturas para a segregação dos resíduos na escola. Dessa forma, todo resíduo gerado era destinado à coleta pública, exceto uma parcela de resíduos orgânicos destinada à alimentação de animais.

Após as práticas de EA, a direção da escola adquiriu coletores (Figura 5). Dessa forma, iniciou a separação, que resultou em expressiva redução na quantidade de resíduos (Tabela 2). Os coletores foram fundamentais na obtenção dos bons resultados, demonstrando que a infraestrutura é necessária para oferecer condições de implantação do processo de gestão dos resíduos. Deve-se considerar ainda que a separação de resíduos foi um dos temas mais abordados nas atividades realizadas com os alunos.

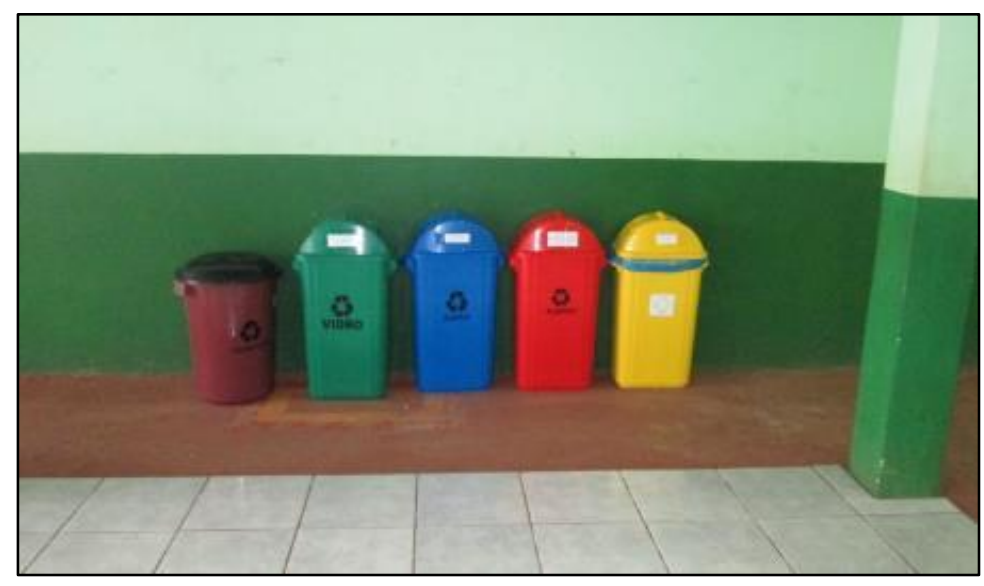

Figura 5: Coletores para segregação

Fonte: Arquivo pessoal.

Nas pequenas, médias e grandes cidades, a escola é uma das principais instituições responsáveis pela educação dos indivíduos e, consequentemente, da sociedade. A importância de temas relativos à coleta seletiva e à reciclagem de resíduos sólidos urbanos, no ensino formal, motiva para a conservação do meio ambiente por meio de práticas adequadas. A EA estimula valores morais $e$ de respeito à vida, propondo reflexões sobre a nossa postura perante as outras pessoas e perante o Planeta. A partir dessa interação se identifica a fundamental importância da EA nas escolas e na sociedade para a correta destinação dos RSU (TÁVORA, 2012).

Durante o desenvolvimento das atividades constatou-se que os estudantes replicam o comportamento dos colegas, auxiliando na disseminação 
das ações. A vivência em grupo possibilita novas formas de pensamento, proporcionando uma visão mais ampliada, compreendendo distintas possibilidades de lidar com um problema (SANTOS, 2009).

Souza et al. (2013) afirmam que comportamentos ambientalmente corretos são aprendidos na prática e a escola contribui significativamente para que essa prática aconteça, formando sujeitos críticos e reflexivos, que sejam capazes também de atuar na complexa realidade socioambiental.

As atividades desenvolvidas na escola respeitaram as características culturais dos estudantes, uma vez que foram desenvolvidas com auxílio da pedagoga, utilizando recursos que fazem parte do cotidiano desses mesmos alunos. Desta forma, a condução das atividades atendeu às recomendações dos Parâmetros Curriculares Nacionais, documento educacional que indica que a EA deve estar inserida na realidade local, de modo a que os alunos absorvam com maior intensidade as informações por fazerem parte do seu cotidiano (BRASIL, 1997).

Além disso, a prática educativa divertida envolve o estudante, prende a sua atenção e fortalece a interação com o professor. A aprendizagem lúdica e prazerosa proporciona o fortalecimento de relações cognitivas através das experiências vividas. Assim, docentes e discentes, ao interagirem, são capazes de transformar o conhecimento em um processo contínuo de construção (MOURA et al., 2016).

$\mathrm{Na}$ análise do Projeto Político-Pedagógico (PPP) constatou-se que as disciplinas de Geografia e de Ciências abordam conceitos de preservação dos recursos naturais e do meio ambiente. Segundo a diretora da escola, esses conteúdos são abordados em sala de aula por meio de vídeos e de materiais complementares vinculados às disciplinas. Mesmo assim, no entanto, constatouse que nenhuma das atividades descritas no PPP ou nas disciplinas citadas aborda diretamente resíduos sólidos urbanos.

No Brasil existe uma tendência de interagir com as questões ambientais como tópicos nas disciplinas de Ciências e de Biologia. Essa tendência de ensino reduz a possibilidade de uma abordagem variada, ética e política das questões ambientais, reduzindo apenas a questões biológicas (GRUN, 2000).

Da mesma foram, Ferrari e Zancul (2016) identificaram que os PPPs, das unidades escolares pesquisadas, eram desprovidos de conteúdos sistematizados e não contemplavam uma visão sobre a temática ambiental. $O$ conteúdo da área não era tratado como tema essencial ao processo educativo nem como tema transversal.

Segundo Ramos (2006), existem outras falhas no processo, como a não compreensão do repertório ambiental por parte dos professores, dificuldades na organização de projetos de forma sistemática e a limitação das escolas no envolvimento em projetos ambientais de forma coletiva, isso além da mencionada falha que é considerar que a EA está relacionada somente a 
processos pontuais e a alternativas de melhoria. Ao contrário, o processo deve ser mais profundo, principalmente em novas políticas públicas (BELLINE, 2010).

A repetição do questionário buscou identificar o conhecimento dos estudantes acerca dos resíduos sólidos urbanos após as atividades de EA. As perguntas foram respondidas por 127 alunos, quantidade inferior às respostas da primeira etapa. Assim os resultados, apresentados na Tabela 3, consideraram 127 questionários.

Tabela 3: Questões respondidas pelos alunos, antes de e após a EA

\begin{tabular}{|c|c|c|}
\hline Questões & Antes a EA & Após a EA \\
\hline 1 - Você joga lixo no chão? & $\%$ & $\%$ \\
\hline Sim & 21,26 & 4,72 \\
\hline Não & 78,74 & 95,28 \\
\hline \multicolumn{3}{|c|}{$\begin{array}{l}2 \text { - } 0 \text { que você faz quando vê alguém jogando lixo no } \\
\text { chão? }\end{array}$} \\
\hline Nada & 21,26 & 11,81 \\
\hline Recolhe & 26,77 & 40,16 \\
\hline Fala que é errado & 51,97 & 48,03 \\
\hline \multicolumn{3}{|c|}{3 - Você sabe o que é compostagem? } \\
\hline Sim & 17,32 & 70,08 \\
\hline Não & 68,50 & 14,17 \\
\hline Talvez & 14,17 & 15,75 \\
\hline \multicolumn{3}{|c|}{4 - Você sabe o que é reciclagem? } \\
\hline Sim & 71,65 & 88,19 \\
\hline Não & 23,62 & 7,09 \\
\hline Talvez & 4,72 & 4,72 \\
\hline \multicolumn{3}{|c|}{5 - Você sabe o que é coleta seletiva? } \\
\hline Sim & 24,41 & 64,57 \\
\hline Não & 64,57 & 19,69 \\
\hline Talvez & 11,02 & 15,75 \\
\hline \multicolumn{3}{|c|}{6 - Na sua casa o lixo é separado? } \\
\hline Sim & 50,39 & 68,50 \\
\hline Não & 45,67 & 25,20 \\
\hline Talvez & 3,94 & 6,30 \\
\hline \multicolumn{3}{|c|}{7 - Você sabe como separar o lixo? } \\
\hline Sim & 66,14 & 90,55 \\
\hline Não & 28,35 & 4,72 \\
\hline Talvez & 5,51 & 4,72 \\
\hline \multicolumn{3}{|c|}{$\begin{array}{l}8 \text { - Você faz alguma coisa para colaborar com o meio } \\
\text { ambiente? }\end{array}$} \\
\hline Sim & 64,57 & 78,74 \\
\hline Não & 26,77 & 8,66 \\
\hline Talvez & 8,66 & 12,60 \\
\hline \multicolumn{3}{|c|}{9 - Você sabe para onde vai o lixo da sua casa? } \\
\hline Sim & 39,37 & 70,08 \\
\hline Não & 45,67 & 22,83 \\
\hline Talvez & 14,96 & 7,09 \\
\hline
\end{tabular}

Fonte: Autores. 
$\mathrm{Na}$ análise dos resultados apresentados, nessa Tabela 3 é possível identificar que as maiores diferenças percentuais, entre o antes e o depois, estão relacionadas a questões teóricas, que refletem a compreensão dos alunos quanto às informações repassadas, como pode ser evidenciado nas questões três e cinco, nas quais o percentual que indica melhora na compreensão dos conceitos foi superior a $40 \%$.

Diferentemente, contundo, as questões que representam a aplicação do conteúdo, especialmente no ambiente familiar, representado nas questões dois, seis e oito, o percentual de variação não atingiu $20 \%$. Esses resultados refletem o apresentado na Tabela 1, indicando que os estudantes não exercem grande influência na gestão dos resíduos em ambiente familiar, diferentemente do que ocorreu na escola, em que a melhora na gestão dos resíduos foi significativa.

Nesse contexto, pode-se afirmar que o processo de EA não deve ocorrer somente na escola, mas, de modo constante, em um conjunto de ações sincrônicas na sociedade e por meio de processos de sensibilização ininterruptos, aprimorados, ideológicos, reflexivos e fundamentados. Como ação de conscientização mútua deve ser continuada por meio de diversas informações e transformação constante da realidade (LOUREIRO, 2006). Assim, portanto, segundo Philippi Jr. e Pelicioni (2005), é necessário entender que a EA precisa ser um processo em constante construção, precisa ser flexível aos acontecimentos cotidianos, o que não acontece no município pesquisado.

A conscientização da comunidade escolar pode proporcionar iniciativas que ultrapassem o ambiente acadêmico, atingindo os demais integrantes da comunidade, professores e funcionários, que podem se tornar multiplicadores das atividades e dos questionamentos gerados da EA na escola (CARNEIRO et al., 2016).

Para que a EA seja de fato transformadora é necessário compreender a interação homem-ambiente e que a sociedade seja mais crítica, que não aceite as informações sem procurar obter respostas plausíveis (BARRA, 2004; TOFFOLO; FRANCISCHETT, 2012). A sociedade deve mudar e estabelecer relações entre as classes e o meio. O paradigma está na educação e não somente na Educação Ambiental (LOUREIRO, 2006).

Além disso, a EA deve ser uma política pública prioritária na busca pelo desenvolvimento sustentável. Ela deve ser considerada um instrumento de gestão ambiental importante para que a sustentabilidade seja materializada (GASQUES et al., 2016).

A prática da coleta seletiva, por exemplo, funciona apenas quando a população, nas suas residências, faz a correta segregação dos RS. Para isso, os cidadãos precisam estar informados, conscientes e motivados para colaborarem com o processo de coleta seletiva (ABRELPE, 2012). 


\section{Conclusões}

As análises dos dados e das atividades desenvolvidas nessa pesquisa mostraram que as ações de EA não tiveram resultado positivo no ambiente familiar. No ambiente escolar, no entanto, os resultados das ações foram favoráveis e uma expressiva melhora pôde ser observada. O resultado satisfatório se deve, possivelmente, à inserção dos coletores no ambiente escolar, o que possibilitou estrutura para a segregação dos resíduos e demonstrou o comprometimento da instituição. Além disso, o projeto políticopedagógico da escola indicou que as questões relacionadas a resíduos sólidos não são abordadas de forma direta e objetiva.

\section{Referências}

ABES. Associação Brasileira de Engenharia Sanitária e Ambiental. Informativo Eletrônico da Associação Brasileira de Engenharia Sanitária e Ambiental. Revista Lixão é Problema em Cidades Pequena, n. 287, 25 de julho de 2012.

ABRELPE - Associação Brasileira das Empresas de Limpeza Pública e Resíduos Especiais. Panorama dos resíduos sólidos no Brasil 2012. São Paulo: ABRELPE, 2012.

ABRELPE - Associação Brasileira de Empresas de Limpeza Pública e Resíduos Especiais. Panorama dos resíduos sólidos no Brasil 2015. São Paulo: ABRELPE, 2015.

BARCELOS, V. Educação ambiental: sobre princípios, metodologias e atitudes. Petrópolis, RJ: Vozes, 2008.

BARRA, V.M.M. Educação ambiental e cidadania. Curitiba, PR: IESDE, 2004.

BELLINI, L.M. Educação ambiental: referenciais para a prática política e científica. 2. ed. Maringá, PR: EDUEM, 2010.

BRASIL. Secretaria de Educação Fundamental. Parâmetros curriculares nacionais: meio ambiente e saúde. Brasília/DF, 1997.

BRASIL. Lei no 12.305, de 2 de agosto de 2010. Política Nacional de Resíduos Sólidos. Diário Oficial [da] República Federativa do Brasil. Poder Executivo, Brasília, DF, 3 ago. 2010.

CARNEIRO, B.S.; OLIVEIRA, M.A.S.; MOREIRA, R.F. Educação Ambiental na Escola Pública. Revbea, São Paulo, v. 11, n. 1, p. 25-36, 2016.

CDCC. Centro de Divulgação Científica e Cultural. Universidade de São Paulo. São Carlos: Centro de Divulgação Científica e Cultura. Destinos do Lixo. 5 min. Disponível em: <https://www.youtube.com/watch?v=nAKkaf0B/hA >. Acesso em: 8 abr. 2014. 
CDCC. Centro de Divulgação Científica e Cultural. Universidade de São Paulo. São Carlos: CDCC. Lixo - responsabilidade de cada um. 10 min. 2002. Disponível em: <https://www.youtube.com/watch?v=VVInzN Ti5k>. Acesso em: 8 abr. 2014.

CONAMA. Conselho Nacional do Meio Ambiente. Resolução no 275, de 25 de abril de 2001. Diário Oficial da República Federativa do Brasil. Poder Executivo, Brasília, DF, 19 jun. 2001. Seção 1, p. 80.

DOHME, V. Atividades lúdicas na educação: o caminho de tijolos amarelos do aprendizado. 4. ed. Petrópolis, RJ: Vozes, 2008.

FERRARI, A.H.; ZANCUL, M.C.S. Aproximações entre os contextos local e nacional em práticas de educação ambiental na escola. Revbea, São Paulo, v. 11, n. 1, p. 66-84, 2016.

FERREIRA, J.A. Resíduos sólidos: perspectivas atuais. Rio de Janeiro: Fiocruz, 2000.

GASQUES, A.C.F.; OKAWA, C.M.P.; SANTOS, J.D.; GASQUES, E.G.F.; $\mathrm{DELABIO}, \mathrm{F}$. Educação ambiental: estudo de caso em dois colégios estaduais da cidade de Sarandi/PR. Revbea, São Paulo, v. 11, n. 5, p. 123-138, 2016.

GRUN, M. Ética e educação ambiental: a conexão necessária. Campinas, SP: Papirus, 2000.

IBGE. Instituto Brasileiro de Geografia e Estatística. Disponível em: $<$ http://www.ibge.gov.br>. Acesso em: 5 nov. 2013.

KOENIG, C. Tá limpo! Rio de Janeiro: Época 10 Comunicações, 1991. $10 \mathrm{mim}$. Disponível em: <https://www.youtube.com/watch?v=mVnX2ZGlo3k>. Acesso em: 14 abr. 2014.

LIMA, L.M.Q. Lixo: tratamento e biorremediação. 3. ed. São Paulo: Hemus, 2004.

LOUREIRO, C.F.B. Trajetória e fundamentos da educação ambiental. 2. ed. São Paulo: Cortez, 2006.

MEC. Ministério da Educação. De onde vem? TV Escola. Disponível em: $<$ http://tvescola. mec.gov.br/tve/videoteca-series!loadSerie?idSerie=312>.

Acesso em: 9 abr. 2014.

MOURA, J.S.T.; CRIBB, S.L.S.P.; JEOVANIO-SILVA, A.L. Vivência de atividades práticas e lúdicas na educação ambiental de crianças de 4-5 anos: o despertar da consciência ecológica e estímulo à motivação profissional e interação aluno-professor. Revbea, São Paulo, v. 11, n. 1, p. 361-384, 2016.

NEVES, M.G.F.P.; TUCCI, C.E.M. Composição de resíduos de varrição e resíduos carreados pela rede de drenagem, em uma bacia hidrográfica urbana. Engenharia Sanitária e Ambiental, Rio de Janeiro, v. 16, n. 4, p. 331336, 2011. 
PHILIPPI JR, A.; PELICIONI, M.C.F. Educação ambiental e sustentabilidade. Barueri, SP: Manole, 2005.

PROJETO POLÍTICO-PEDAGÓGICO. Escola Municipal Eça de Queirós. Manfrinópolis-PR, 2012.

RAMOS, E.C. A abordagem naturalista na educação ambiental - uma análise dos projetos ambientais de educação em Curitiba. 2006. $232 \mathrm{f}$. Tese (Doutorado em Ciências Humanas). Universidade federal de Santa Catarina, Florianópolis, 2006.

RIBEIRO, D.V.; MORELLI, M.R. Resíduos sólidos: problemas ou oportunidade? Rio de Janeiro: Interciência, 2009.

SANTOS, L.M.M. A importância de práticas de ensino criativas na Educação Ambiental. Anais do VII Encontro Nacional de Pesquisa em Educação em Ciências. Florianópolis, nov. 2009.

SOUZA, G.S.; MACHADO, P.B.; REIS, V.R.; SANTOS, A.S.; DIAS, V.B. Educação ambiental como ferramenta para o manejo de resíduos sólidos no cotidiano escolar. Revbea, Rio Grande, v. 8, n. 2, p. 118-130, 2013.

TÁVORA, M.A. Práticas e reflexões sobre a educação ambiental na escola pública: a gestão de resíduos sólidos na E. E. F. M Cel. Murilo Serpa, em Itapipoca - CE. Revbea, Rio Grande, v. 7, n. 1, p. 37-43, 2012.

TOFFOLO, G.; FRANCISCHETT, M.N. Educação ambiental: na perspectiva da pesquisa qualitativa. Cascavel, PR: Editora da Unioeste, 2012.

VYGOTSKY, L.S. Formação social da mente. 7. ed. São Paulo: Martins Fontes, 2007. 